Earth science

\section{Microseismicity data forecast rupture area}

0

n 28 September 2004 there was an earthquake of magnitude 6.0 at Parkfield, California. Here we show that the size distribution of the micro-earthquakes recorded in the decades before the main shock occurred allowed an accurate forecast of its eventual rupture area. Applying this approach to other well monitored faults should improve earthquake hazard assessment in future.

The Parkfield event fulfilled, in terms of location and size, the forecast made 20 years ago in the Parkfield earthquake-prediction experiment ${ }^{1}$. However, the course of the rupture came as a surprise: it started in the southern end of the rupture zone of the last magnitude- 6.0 event of 1966 and continued mainly to the north. The timing of the earthquake was not predicted, and no short-term precursors were reported before the event.

We are able to demonstrate that the rupture area of the Parkfield event accurately matches our earlier forecast ${ }^{2}$, which was derived from the size distribution of the microseismicity in the three decades before the event.

The cumulative earthquake-size distribution is commonly described by a power law: $\log N=a-b M$, where $N$ is the cumulative number of earthquakes of magnitude $M$ or greater, $a$ is the earthquake productivity of a volume, and $b$ is the relative size distribution $^{3}$. In the laboratory, $b$ values have long been known to be inversely dependent on differential stress ${ }^{4}$. If this dependence holds in the Earth's crust, then measurements of spatial and temporal changes in $b$ could act as a 'stressmeter' to help image asperities - the highly stressed patches in faults where future ruptures are likely. The Parkfield event in September 2004 allowed us to test this idea ${ }^{2,5}$.

Figure 1a is a map view of the fault that shows the area of low $b$ values around Parkfield. Figure $1 \mathrm{~b}$ is a high-resolution image of $b$ values along the fault ${ }^{5}$, obtained from seismic activity in the magnitude range 1.3 to 5 between January 1981 and September 2004. We interpret the unusually low $b$ values in the Parkfield area as an indication of highly stressed patches in the fault (Fig. 1b). The preliminary slip distribution of the 2004 main shock ${ }^{6}$, and the aftershocks that occurred in the first week, are shown in Fig. 1c, d. The areas of low $b$ value contain $99 \%$ of the slip and $95 \%$ of the aftershocks (Fig. 1e,f). Areas of high $b$ value, which in the past we interpreted as creeping sections, act as barriers against rupture propagation. Two magnitude-5 aftershocks occurred within two days of the main event in the last remaining area of low $b$ value that had been left unruptured by the main shock (Fig. 1b, c).

The close match we find between the area

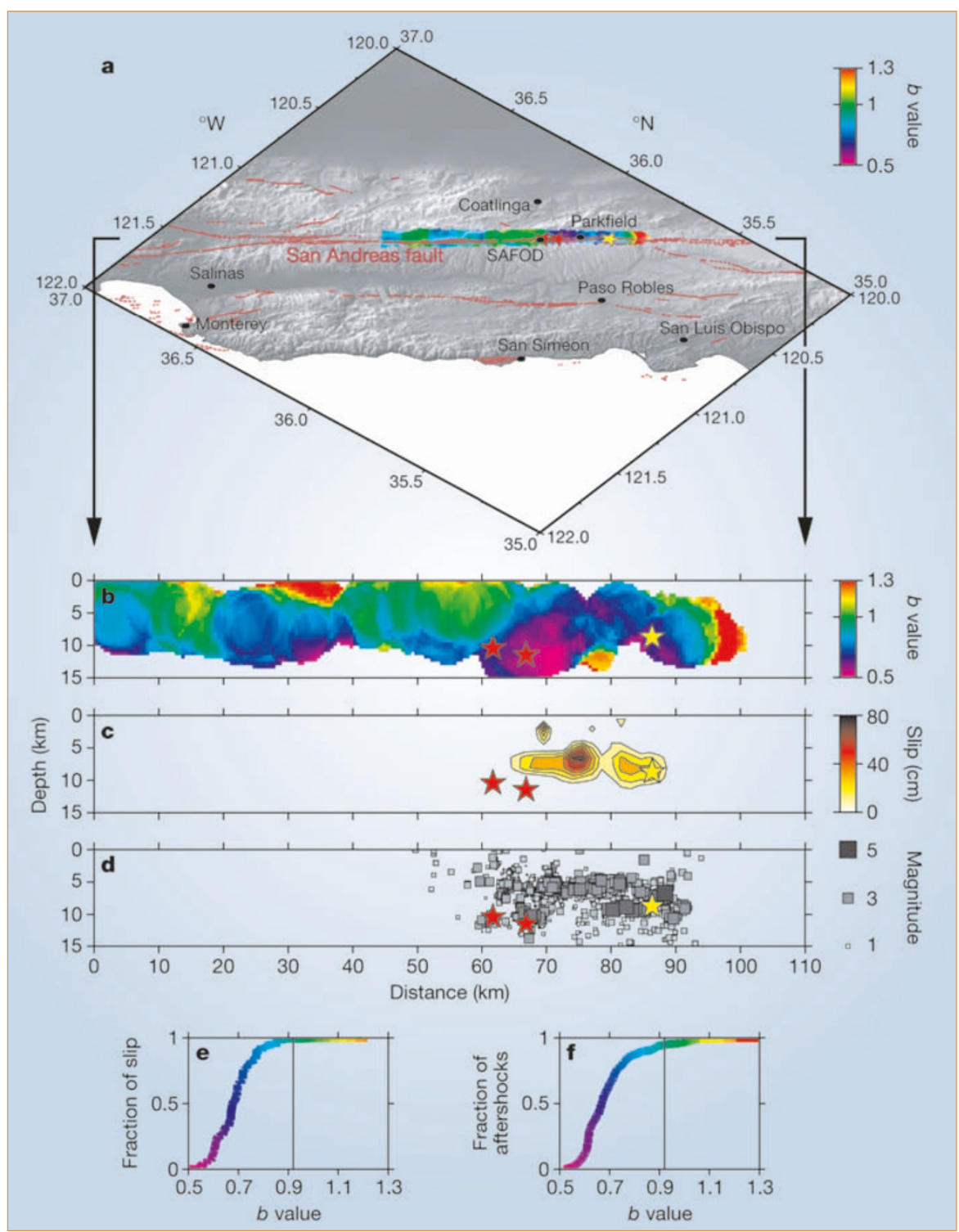

Figure 1 Cross-sectional views of the San Andreas fault at Parkfield. a, Topographic map of the Parkfield region with mapped $b$ values. Red lines mark faults. Yellow stars, magnitude-6.0 main shock; red stars, magnitude-5.0 aftershocks. b, Microseismicity $b$ values from 1981 to 27 September 2004 mapped along the cross-section. c, Preliminary slip distribution for the main shock that occurred on 28 September 2004. d, Aftershocks (28 September to 5 October) of the magnitude-6.0 event on 28 September 2004; symbol size is proportional to magnitude. e, Cumulative slip distribution as a function of $b$ value; line colour corresponds to the $b$ value. The vertical line indicates the regional average $b$ value of 0.92 . f, As $\mathbf{e}$, but showing the cumulative distribution of aftershocks.

of low $b$ values and the observed rupture area indicates that $b$ values may indeed act as stressmeters for the Earth's crust. Our observations support previous retrospective studies $^{7}$ that correlated patches of low $b$ value, based on recent microseismicity, with the main shocks at Izmit (Turkey), Kanto (Japan), the San Jacinto-Elsinore fault zone (California) and Morgan Hill (California).

The combined evidence indicates that $b$ values could be used for accurately predicting rupture areas: although the timing of earthquakes remains unpredictable, precise forecasting of the location and size of events is becoming a possibility.

\section{Danijel Schorlemmer, Stefan Wiemer}

Swiss Seismological Service, ETH Zürich, 8093

Zürich, Switzerland

e-mail:danijel@sed.ethz.ch
1. Roeloffs, E. \& Langbein, J. Rev. Geophys. 32, 315-335 (1994).

2. Wiemer, S. \& Wyss, M. J. Geophys. Res. 102, 15115-15128 (1997).

3. Gutenberg, R. \& Richter, C. F. Bull. Seismol. Soc. Am. 34, 185-188 (1944).

4. Scholz, C. H. Bull. Seismol. Soc. Am. 58, 399-415 (1968).

5. Schorlemmer, D., Wiemer, S. \& Wyss, M. J. Geophys. Res. 109, B12307 (2004)

6. Ji, C. et al. EOS Trans. AGU 85(47), Fall Meet. Suppl., Abstr. S53D-04 (2004).

7. Wiemer, S. \& Wyss, M. Adv. Geophys. 45, 259-302 (2002).

Competing financial interests: declared none.

\section{brief communications arising online}

\section{www.nature.com/bca}

Fisheries: Decline of Pacific tuna populations exaggerated?

J. Hampton, J. R. Sibert, P. Kleiber, M. N. Maunder, S. J. Harley (doi:10.1038/nature03581)

Reply: R. A. Myers, B. Worm (doi:10.1038/nature03582) 